\title{
Valerio Petrarca, Un prophète noir en Côte- d'Ivoire. Sorcellerie, christianisme et religions africaines
}

Trad. de Marie-José Hoyet. Paris, Karthala, 2008, 276 p.

\section{André Mary}

\section{OpenEdition \\ Journals}

Édition électronique

URL : http://journals.openedition.org/assr/21642

DOI : $10.4000 /$ assr.21642

ISSN : $1777-5825$

Éditeur

Éditions de l'EHESS

Édition imprimée

Date de publication : 31 décembre 2009

ISBN : 978-2-7132-2218-4

ISSN : 0335-5985

Référence électronique

André Mary, « Valerio Petrarca, Un prophète noir en Côte-d'Ivoire. Sorcellerie, christianisme et religions africaines ", Archives de sciences sociales des religions [En ligne], 148 | octobre-décembre 2009,

document 148-104, mis en ligne le 15 novembre 2012, consulté le 21 septembre 2020. URL : http:// journals.openedition.org/assr/21642; DOI : https://doi.org/10.4000/assr.21642

Ce document a été généré automatiquement le 21 septembre 2020.

(C) Archives de sciences sociales des religions 


\section{Valerio Petrarca, Un prophète noir en Côte-d'Ivoire. Sorcellerie, christianisme et religions africaines}

Trad. de Marie-José Hoyet. Paris, Karthala, 2008, 276 p.

\section{André Mary}

\section{RÉFÉRENCE}

Valerio PETRARCA, Un prophète noir en Côte-d'Ivoire. Sorcellerie, christianisme et religions africaines, Trad. de Marie-José Hoyet. Paris, Karthala, 2008, 276 p.

148-104

Cet ouvrage est la traduction en français d'une thèse publiée en italien en 2000 aux éditions Vieilla Liberia Editrice (Roma). Il porte sur un personnage prophétique dénommé Koudou-Gbahié, connu sur la scène politico-religieuse ivoirienne sous le nom familier de "Koudou Jeannot». Cet avatar relativement récent de la tradition prophétique ivoirienne est devenu particulièrement célèbre à la suite de son arrestation, en 1986, par la police d'État et de son emprisonnement sans procès pendant plus d'un an, un scénario qui rappelle et répète la grande geste prophétique d'Harris des années dix. Les anthropologues (J.-P. Dozon, La cause des prophètes, Seuil, 1995) l'ont déjà intégré dans la généalogie des figures prophétiques locales et ses campagnes d'éradication des fétiches au sein des villages ont suscité les réactions critiques d'une historienne comme C.-H. Perrot dénonçant les menaces que de telles entreprises font peser sur le patrimoine culturel et sur les gardiens de la tradition («Prophétisme et modernité en Côte d'Ivoire », in J.-F. Bayard, Religion et modernité politique en Afrique Noire, Karthala, 1993).

2 L'apport ethnographique original de Valerio Petrarca s'appuie sur un terrain de deux mois mené, en 1998, en pays Dida, près de Lakota, investissant la vie quotidienne du prophète désormais replié sur son lieu cultuel et son village thérapeutique. Sa 
contribution majeure à la documentation du phénomène est le recueil d'un récit autobiographique du prophète, un genre assez rare dans une tradition villageoise d'individus analphabètes qui ne connaissent la Bible que par la transmission orale de la prédication missionnaire. Mais l'ouvrage en profite aussi pour revenir, dans la confrontation de l'expérience individuelle et des typologies, sur les enjeux de la construction du phénomène prophétique dans l'Afrique d'aujourd'hui. Au regard des tensions classiques entre la figure du prophète itinérant, passeur de frontières, et $d u$ prophète fondateur de culte "en son pays", du prophète contre-sorcier appelant à rompre avec les fétiches et de l'agent de la conversion à la force du Dieu des Blancs, le cas de Koudou-Gbahié est exemplaire et mérite le détour. L'auteur en fait un «messie des synthèses " et invite à lire ce culte chrétien anti-sorcellerie comme un produit synthétique; il ne dit pas «syncrétique » car le travail d'élaboration de la cosmogonie autant que du rituel liturgique est, de fait, particulièrement construit et réfléchi.

3 Koudou-Gbahié est d'abord le produit « en double » de son grand frère Gbahié, mort jeune dans des circonstances troubles, et dont l'esprit a commencé par "posséder» Koudou et parler par sa bouche pour annoncer la mort de Gbahié en « martyr », victime de la sorcellerie de ses proches parents. Sur le plan anthropologique, cette possession prophétique qui se transmue parfois en transe visionnaire pour légitimer l'accusation de sorciers désignés et nommés est une première synthèse remarquable des registres de l'ordalie (interrogation du cadavre), de la possession et de la vision, de l'accusation et de la confession, pratiqués par tous les prophètes ivoiriens chacun à sa façon, le plus célèbre étant sans doute le prophète guérisseur Atcho (dont bizarrement d'ailleurs l'auteur ne parle pas). La généalogie de ce précipité prophétique se réfère à la grande figure d'Harris, connu surtout par la tradition des Églises harristes, mais surtout à Bagué Honoyo, dite Marie Lalou, la fondatrice de l'Église Deima, que Koudou appelle sa « maman » (non sans lien de parenté indirecte), sans reprendre pour autant l'héritage de son Église et de ses disciples. La surprise, c'est la présence dans ces figures d'identification d'un prêtre catholique "charismatique» Dida, le Père Dago, qui reconnaît disposer lui aussi de pouvoir de voyance et de guérison pour lutter contre la sorcellerie et mise sur l'alliance avec Koudou au grand scandale de la haute autorité de Monseigneur Yago. La synthèse symbolique de Koudou est en effet fortement ancrée dans toute une cosmogonie "païenne" de la Terre mère associée au culte et au pèlerinage qui entourent la tombe de Gbahié mais elle conjugue dans la liturgie le serment ordalique à la Terre mettant à l'épreuve les sorciers, et la force symbolique du catholicisme et de ses symboles pour retourner le mal d'où il vient. Dans la formule de ce christianisme anti-sorcellerie, Koudou mobilise en fait, en pratiquant un dédoublement bien connu (sorcellerie blanche/sorcellerie noire), l'esprit des " chrétiens blancs ", celui des «bons pères » missionnaires, auxquels il garde toute sa confiance, contre les "chrétiens noirs ", les pires. Si Koudou se découvre "prophète " par la possession de l'esprit de son frère mort, ce dernier se transfigure par la parole de Koudou en "martyr", une catégorie là aussi synthétisant le statut de victime sorcellaire au destin christique (Jésus est ici une victime des sorciers) et celui de figure tutélaire ancestrale associée aux forces de la Terre et de la forêt.

4 La grande nouveauté sur le plan sociologique, c'est la logique d'inversion qui caractérise l'orientation des accusations de sorcellerie dans les affaires villageoises et le rôle d'embrayeur de violence, pour reprendre les termes de J. Favret-Saada, que joue ici le prophète. Dans la sociologie «traditionnelle » des situations coloniales, ce sont les vieux, chefs de culte et notables, qui contrôlent le jeu de l'accusation et ce sont les 
jeunes ambitieux, enrichis par la vie urbaine, ou les femmes insoumises ou divorcées, qui menacent l'ordre coutumier en prétendant s'élever au-dessus de leur place statutaire et se voient accusés de sorcellerie par les devins-guérisseurs. Dans le dispositif de campagne de Koudou-Jeannot, ce sont, au contraire, les jeunes de la ville, étudiants, salariés, qui interpellent le prophète et forcent la main aux vieux pour qu'ils viennent faire la chasse aux sorciers et aux féticheurs responsables de l'accumulation des malheurs. Les règles de plausibilité de l'accusation sont donc totalement inversées, ce qui déstabilise l'ordre villageois fondé sur la chefferie et la prêtrise des cultes mais menace aussi le pouvoir des Grands qui a toujours fait alliance avec les chefferies traditionnelles et les Monseigneurs.

5 C'est ici que le vaste détour historique, sociologique et politique auquel nous invite l'auteur, et qui a pour motif premier les causes de la mort de Gbahié vers la fin des années cinquante, se révèle particulièrement éclairant et pertinent. Ce jeune homme dynamique et entreprenant faisait partie de la nouvelle génération de ces lettrés qui ont connu l'expérience migratoire en France (en l'occurrence comme militaire) pour revenir investir dans l'économie de plantation qui a fait le miracle ivoirien. D'une certaine façon, ce sont les fils ou petit-fils d'Houphouët-Boigny, le "vieux », le grand planteur qui a déboisé la forêt, le syndicaliste et militant politique, futur Père de l'Indépendance du pays. Mais tout le problème est que ce "roi Baoulé » a géré dès le départ la Côte-d'Ivoire comme un grand "sorcier" et pratique une politique du fétichisme et de l'accusation de sorcellerie qu'il n'a cessé de retourner contre toute cette génération intellectuelle et politique considérée comme un vivier d'opposants et de comploteurs contre l'État. Le tableau que l'auteur nous retrace de la sorcellerie comme politique d'État avec ses complots, ses accusations, ses arrestations et ses assassinats, est impressionnant même s'il doit beaucoup à l'ouvrage de Diarra Samba (Les faux complots d'Houphouet-Boigny. Fracture dans le destin d'une nation (1959-1970), Karthala, 1997). Le rapprochement s'impose avec la guerre civile récente et le régime actuel de la Côte-d'Ivoire (pour ceux qui pensent et qui disent qu'avec le Vieux, ce n'était pas comme cela). Si la mort trouble de Gbahié s'inscrit, à l'origine, dans une multiplication d'autres morts de la parenté proche et dans une affaire de sorcellerie rapidement rabattue sur le monde villageois, le contexte politique de lutte contre les « sorciers du monde » et l'imaginaire de la « contamination universelle » qui inspire le combat dans lequel Koudou Jeannot se trouve désormais engagé, imposent un recadrage en grande partie suscité par la politique sorcellaire de l'État ivoirien qu'il affronte, et qui finira d'ailleurs par l'arrêter et l'emprisonner en répétant le scénario du «martyre ». L'interprétation des enjeux locaux et de la crise intergénérationnelle fait appel entre-temps à une grille de lecture globale des pouvoirs de vie et de mort qui transcende et articule les mondes urbains et villageois, celui des fonctionnaires salariés et des agriculteurs.

6 La lecture politique de la transmutation de ce culte anti-sorcellerie en un mouvement de contestation de la nuisance des pouvoirs traditionnels et de dénonciation de la politique du ventre d'un État allié à l'Église (symbolisée par la basilique de Yamoussoukro) a déjà été cependant largement dressée par J.-P. Dozon. C'est dans l'analyse du repli cultuel du prophète libéré et de l'invention d'une Église disposant d'une liturgie et d'une cosmogonie que se situe le complément attendu de cette étude et sa contribution documentaire est au rendez-vous. Mais pour faire parler ces données descriptives, il manque une analyse comparative, au moins régionale, des autres entreprises prophétiques, cultuelles et thérapeutiques, antérieures ou contemporaines. 
La distance affichée de Koudou-Gbahié par rapport à l'Église Deima imposait de prendre des marques et de situer les écarts. On s'étonne surtout que les études consacrées à la communauté prophétique d'Albert Atcho (plus anciennes sans doute) soient à ce point ignorées et même absentes de la bibliographie. Que dire de l'entreprise très proche du prophète Odjo, étudiée par Marc Augé et filmée par J.-P. Colleyn (Nkpiti, La rancune et le Prophète, Augé M., Colleyn J.-P., Paris, EHESS, 1990) jamais citée non plus.

7 Au-delà de la modestie d'une étude soucieuse de documentation, l'auteur nous offre une vraie contribution à l'analyse des ressorts du travail prophétique inspirée des réflexions de $\mathrm{M}$. Augé sur le sens de la force et la force du sens, l'arbitraire des pouvoirs de vie et de mort. Le comparatisme aurait néanmoins permis d'approfondir l'enjeu autour duquel tourne l'auteur : la synthèse prophétique est-elle en définitive païenne ou chrétienne? Ni l'un, ni l'autre, ou les deux à la fois. La question n'est pas naïve puisque les anthropologues comme M. Augé ou J.-P. Dozon ont pu lire dans l'itinéraire de Koudou Jeannot une sorte de retour du "paganisme ", un néo-traditionnalisme marquant sa distance, dans le contexte politique actuel, vis-à-vis du christianisme. L'apport de cette étude est manifestement de souligner, au contraire, la matrice chrétienne de ce montage prophétique même si l'oscillation est la règle du jeu de cette synthèse. Pour sortir vraiment du "rituel anthropologique ivoirien » qui s'évertue à relire, comme le souligne l'auteur lui-même en conclusion, les prophétismes en termes d'avatars du paganisme, il faudrait élargir un peu plus la focale, et prendre la mesure $\mathrm{du}$ vaste développement des prophétismes évangéliques et des mouvements charismatiques de guérison qui ont marqué la naissance même de la vocation de Koudou (voir son alliance avec le prêtre charismatique Dago) et qui débordent aujourd'hui de toute part les prophètes « en leur pays ». 